\title{
Price Differentials in Monetary Unions: The Role of Fiscal Shocks *
}

\author{
Fabio Canova ${ }^{\dagger}$ and Evi Pappa ${ }^{\ddagger}$
}

This Revision, June 2005

\begin{abstract}
We study the effect of regional expenditure and revenue shocks on price differentials for 47 US states and $9 \mathrm{EU}$ countries. We identify shocks using sign restrictions on the dynamics of deficits and output and construct two estimates for structural price differentials dynamics which optimally weight the information contained in the data for all units. Fiscal shocks explain between 14 and 23 percent of the variability of price differentials both in the US and in the EU. On average, expansionary fiscal disturbances produce positive price differential responses while distortionary balance budget shocks produce negative price differential responses. In a number of units, price differential responses to expansionary fiscal shocks are negative. Spillovers and labor supply effects partially explain this pattern while geographical, political, and economic indicators do not.
\end{abstract}

JEL classification numbers: E3, E5, H7

Key words: Price differentials, Fiscal policy, Monetary unions, Bayesian methods

*We thank Tim Besley and Marco Del Negro for allowing us the use of some of their data. We also thank the editor of this journal, two anonymous referees, A. Vredin, C. Favero, F. Altissimo, N. Kiyotaki, R. Perotti, and D. Quah and the participants of seminars at the Riksbank, the University of Oslo, LSE, LBS, Cambridge, Tor Vergata, QMUL, Lousanne, the conferences "Political, Institutional and Economic Determinants of Fiscal Policy", ESSIM 2003, "Fiscal and monetary policy", the Greek Economic Association conference for comments and suggestions.

${ }^{\dagger}$ Universitat Pompeu Fabra, IGIER and CEPR, Department of Economics, Ramon Trias Fargas 25-27, 08005 Barcelona, Spain, email: fabio.canova@upf.edu

${ }^{\ddagger}$ London School of Economics and IGIER, Department of Economics, Houghton Street, WC2 2AE London, email: p.pappa@lse.ac.uk 


\section{Introduction}

The creation of the European Monetary Union (EMU) came together with a set of rules for membership, known as the "Maastricht criteria", which stressed the need for convergence in the nominal and real side of the economies of candidate countries. The presence of such rules signals the aversion of political leaders to regional dispersions. There is some economic logic behind this concern. For example, differentials in the level of public debt may generate political games where a virtuous region has to bail out a less virtuous one to avoid the collapse of the union. Similarly, differential in price dynamics may interfere with the price stability goal (see e.g. ECB (2003)). While casual observation suggests that differentials in price dynamics are relatively small and die out quickly in the US - a result recently challenged by Cecchetti, Mark and Sonora (2002) - the maximum inflation differential in the Euro area was above two percent for each of the last three years, inflation differentials appear to be persistent and both the heterogeneity and the persistence are expected to increase as the area is enlarged to new entrants (see e.g. Angeloni and Erhmann (2004)).

Should one worry about the existence and the persistence of such differentials? Differentials in productivity may be one of the causes for regional price differential. As the Balassa-Samuelson effect indicates, an increase in the productivity of the traded goods sector in one region, leads to higher regional real wages. This in turn drives the regional relative price of non-traded goods up and, with common prices for traded goods, the price level increases relative to the union average (see e.g. Canzoneri, Valles and Vinals (1996)). When productivity differences are persistent, differentials in output growth and inflation rates could be observed. Such differentials, however, do not necessarily call for restraining actions by federal institutions (see e.g. Duarte and Wolman (2002)).

Demand factors, combined with a large component of non-tradables in the locally consumed basket of goods, may be an alternative cause for regional price differentials. Persistent increases in the demand for non-traded goods may generate localized bursts of inflation whenever the supply of these goods is not perfectly elastic with respect to demand conditions. One component of demand typically tilted towards non-traded and local goods is government expenditure. If local government expenditure is an important source of price differentials and if price differentials pose a threat to union wide inflation stability, Central Banks may want to closely monitor the dynamics of regional fiscal variables (as suggested by Canzoneri, Cumby and Diba (2002)) and federal authorities may

be justified in imposing deficit limits (as the Growth and Stability Pact in the EU) or strict balance budget requirements (as the Graam, Rudman and Hollings amendment in the US). 
Differences in price dynamics are of particular concern in the EMU for two reasons. First, since fiscal variables is controlled by national authorities, political economy type considerations may induce them to use the fiscal trigger disregarding the union-wide consequences. As Perotti (2002) suggested, many of the institutional provisions of the EMU can be rationalized in terms of constraints on local fiscal policy to enable monetary policy to achieve its price stability mandate. Second, the channels through which differential price dynamics are naturally dissipated are either institutionally limited or absent. For example, goods markets are only weakly integrated and labor mobility practically inexistent.

The existence of differentials price dynamics reached the forefront of the policy discussion recently when Ireland received a reprimand by the EU council of Ministers in 2001 for running a rather loose fiscal policy. In fact, in an attempt to attract foreign investment and to reduce budget surpluses, the Irish government cut capital income taxes in 1999 and this was accompanied by large output increases in 2000 and 2001 and a significant inflation differential with the EU average.

This paper empirically studies the relationship between fiscal disturbances and regional price differentials in monetary unions using a sample of 9 European countries and 47 US states. Given the short life of the EMU area, the US experience provides valuable information on how price differentials may evolve in response to unexpected variations in fiscal variables and useful insights on the links between the dynamics of price differentials and the overall rate of inflation. Identifying economically meaningful shocks is always a difficult enterprise and fiscal disturbances are not an exception. Endogeneity of fiscal variables, interactions between fiscal and monetary policy decisions, delays between planning, approval and implementation of policies, and scarceness of reasonable zero restrictions make fiscal disturbances difficult to recover. We circumvent these problems using sign restrictions on the dynamics of output and deficits generated by a large class of DSGE models (see e.g. Baxter and King (1993), Ludvigson (1996), Ohanian (1997), Fatas and Mihov (2001) and Pappa (2004)). Mountford and Uhlig (2002) provide an earlier study where sign restrictions are used to identify fiscal shocks in aggregate US data. We differ in the implementation of the restrictions, in the specification of the VAR and in the estimators we consider. Since sign restrictions are routinely used to check the reasonableness of identification results, it makes sense to impose them directly when extracting the informational content of a reduced form shock.

We identify two types of expenditure shocks: those financed by bond creation, which produce positive comovements in regional expenditure, output and deficits; and those financed by distorting taxation, which leave deficits unchanged and produce negative comovements between expenditure 
and output. For revenue shocks, on the other hand, we concentrate on textbook type shocks, i.e. tax cuts which increase deficits and output.

Given the panel nature of the data, our exercises are concerned in characterizing both average tendencies and in highlighting cross sectional differences. Since the data is short in both T (time) and N (units) and the model dynamic, standard techniques are unsuited for the analysis. The approach we take is Bayesian: we model the cross section of experiments as repeated observations on the same unknown phenomena (the response of regional price differentials to fiscal shocks). We assume that the structural parameters for each unit are drawn from a common prior distribution and we construct posterior distributions which reflect our a-priori assumptions and the information contained in the data.

Our results suggest that, on average, deficit financed expansionary fiscal disturbances increase price differentials, while expansionary fiscal shocks financed by distortionary taxation decrease them. Typically, different fiscal instruments have different quantitative effects. For example in the US, balance budget shocks produce the largest price differentials responses while the most persistent dynamics are produced by expenditure shocks. Also, the timing of the peak response depends on the type of shocks. Overall, fiscal disturbances account for a modest and but nonnegligible portion of price differential variability in both unions (on average, between 14-23 percent).

Several heterogeneities are present at the individual level. For example, in a third of the units expansionary expenditure shocks significantly decrease price differentials and in one fourth expansionary revenue disturbances significantly decrease price differentials. In some cases responses are small and turn positive after one period but in others they are large and, at times, persistent. Puzzling as it might sound, this outcome is consistently reported in analyses conducted with aggregate US data (see e.g. Fatas and Mihov (2001), Canzoneri, Cumby and Diba (2002) or Mountford and Uhlig (2002)) and in some OECD countries (see Perotti (2002)). We find that intuitive explanations based on geographical, political, economic and social considerations can not account for these responses. We investigate two alternative potential explanations. One has to do with geographical spillovers: if either the state is large in size or public (and private) expenditure is tilted toward non-locally produced goods, increases in local demand may also affect prices in neighboring states. If these spillovers matter for union-wide prices, price differentials may decline following expansionary fiscal shocks. The second explanation focuses on aggregate supply movements. If expansionary fiscal shocks exercise an effect on the labor or capital supply of the local economy (as, for example, predicted by RBC-type models), it is possible for temporary output expansions to coexist with 
temporary price differential declines. For the case of revenue shocks, the nature of taxation may also explain the sign and the magnitude of price differential responses. For example, indirect tax shocks could have substantially different labor supply effect than direct labor income or capital tax shocks. Overall, both types of effects are present in the data and partially explain the puzzling price differential responses.

The rest of the paper is organized as follows. The next section describes the reduced form model. Section 3 details the identification restrictions used. Section 4 discusses the econometric procedure. Section 5 presents the results and section 6 concludes.

\section{The reduced form model}

The data available for both monetary unions is short: we have annual data from 1969 to 1995 for US states and quarterly data from 1997:1 to 2003:3 for the EMU nations ${ }^{1}$. The shortness of the data prevents us not only to study issues connected with the transmission of shocks across units but also to be able to analyze medium scale empirical models which simultaneously include local, regional and union wide variables. Given these limitations we are forced to make a number of choices. We initially neglect possible neighborhood effects and model the VAR for each unit using five endogenous variables, a few exogenous variables and a constant for both unions. The endogenous variables are: the log of the local to the union wide price level; the log of the local to the union wide real per-capita GDP; the log of the local to the union wide employment level; the log of local real government revenues and the log of local real direct government expenditure, both in per-capita terms and deflated by local prices. The exogenous variables we include are the area-wide nominal interest rate, the level of oil prices and, for the US, the area-wide deficit and the local debt. Oil prices are used to capture aggregate area-wide supply effects, while with the nominal interest rate and the area wide deficit we attempt to control for aggregate cyclical effects which are demand driven. Favero and Monacelli (2002) estimated fiscal policy rules and found that debt is an important determinant of taxes and expenditures. We include local debt in the specification for US states but exclude it from the EMU models since only annual data, displaying very little variations over the sample, is available. Similarly, we exclude the area-wide deficit from the EMU specification since no federal fiscal authority exists. We use only the direct component of

\footnotetext{
${ }^{1}$ Given that the convergence process was already completed two years before the EMU started, we included 1997 and 1998 data to our sample, even though, strictly speaking they do not belong to the new regime. None of the qualitative conclusions we present are altered by omitting these two years from the sample.
} 
government expenditure since transfers display low frequency movements which could distort our analysis. The sources and the definition of the data are described in appendix A.

While theory indicates that output, employment and deficits are crucial to understand the macroeconomic effects of fiscal policy (see e.g. McGrattan (1994), Duarte and Wollman (2002), Pappa (2003)), in practice, it is not clear how to measure the relevant quantities. For this reason, we also examined several variants where revenues and expenditures are measured in percentage of local GDP; where local GDP per-capita and local employment are not scaled by union wide averages and where the local variables are expressed in growth rates (but not per-capita terms). Furthermore, we have substituted the implicit price deflator for CPI ${ }^{2}$ and checked if there are independent low frequency movements in local variables which may make the interpretation of the results problematic. The results we present are qualitatively invariant to all of these changes.

To claim that the shocks we recover are economically meaningful a number of orthogonality assumptions also need to be made. For example, it is possible that state government expenditure is (positively) correlated with the expenditure of neighboring states or that is (negatively) correlated with union wide expenditure. To examine whether this omission is important, we have run a model where in place of state fiscal variables we use the residual of a preliminary regression of these variables on either union wide variables or the variables of the region where the state (country) is located. The results are unchanged suggesting that, if present, these correlations are small.

Finally, given the data limitations, we use only one lag for each variable. We checked for US states whether the inclusion of a second lag made a difference: it didn't. After a short specification search we settled on making exogenous variables enter only contemporaneously in the system.

\section{The identification restrictions}

While structural VARs have been extensively used to study the transmission of monetary policy shocks, considerably less work has been done to identify fiscal disturbances and to examine their macroeconomic effects. Relevant exceptions include Ramey and Shapiro (1998), Edelberg, Eichenbaum and Fisher(1999), Fatas and Mihov (2001), Mountford and Uhlig (2002), Blanchard and Perotti (2002), Burnside, Eichenbaum and Fisher (2002) and Perotti (2002).

This apparent lack of interest is due, in part, to the fact that fiscal policy is rarely unpredictable. A fiscal change is usually subject to long discussions and political debates before it is implemented.

\footnotetext{
${ }^{2}$ Since Implicit Price Deflator data is available in US states only from 1986 we have reconstructed them backcasting with predictive regressions on CPI data.
} 
These delays make standard innovation accounting problematic: agents adjust their behavior to the new conditions when the old regime still prevails; macrovariables start moving before the shock occurs and no surprise is measurable at the time when the policy change actually takes place. This "non-fundamentalness" problem plagues fiscal shocks more than other types of policy disturbances. A second conceptual problem has to do with the fact that, even when the policy stance is unchanged, expenditures and revenues move with the state of the economy. Hence, it is necessary to separate variations due to exogenous policy shifts from those due to endogenous reactions to the business cycle. Third, as suggested in the fiscal theory of the price level (see e.g. Christiano and Fitzgerald (2001) for a survey), fiscal and monetary policy actions may be related. This was true in the past in many EMU countries were monetary authorities residually satisfied the government budget constraint. Whenever policy decisions are tightly linked, identifying fiscal shocks in isolation from monetary disturbances may be misleading (see e.g. Neri (2002)).

Our set up is designed to avoid, in principle, all these problems. First, because we consider monetary unions, we can take monetary policy as given when examining regional fiscal policy. We do this by imposing the exogeneity of the economy wide interest rate in the model. Second, since all VAR variables are endogenous we can control for the state of the local business cycle while the state of the aggregate economy is automatically factored out by taking real variables in deviation from union wide variables and introducing a number of additional area wide controls. This setup allows for aggregate shocks to exercise different effects in different states; removes the need to produce cyclically adjusted estimates of fiscal variables and allows better separation of predictable and unpredictable movements in the observables. Third, since we precisely define the kind of fiscal disturbances we are looking for and the timing of the responses of the endogenous variables is largely unrestricted, the non-fundamentalness problem is also considerably eased.

In this paper, we seek expenditure shocks with the following characteristics:

- (G shocks) They must produce contemporaneous positive comovements in regional deficit and positive comovements in regional output.

- (BB shocks) They must leave contemporaneous regional deficit unchanged and produce negative comovements in regional output.

The first type of expenditure shocks is the one usually encountered in macroeconomic textbooks, in dynamic RBC or sticky price models (see e.g. Baxter and King (1993) or Pappa (2004)). An unexpected increase in government spending, financed by bond creation, by definition increases 
regional deficit, stimulates aggregate demand and boosts output. In identifying this type of shocks we are agnostic about the behavior of tax revenues: they are allowed to stay unchanged or move together with expenditure as long as the correlation with the latter is not perfect. We are also agnostic about the timing of output responses (they could be contemporaneous, lagged or leading the shock). We do not attempt to distinguish between Keynesian and Neoclassical shocks (see Pappa (2004) for such an exercise). Once shocks are identified, one can indirectly examine the nature of expenditure disturbances using the magnitude of output multipliers.

The second type of shocks we consider are budget-balanced shocks: these disturbances produce instantaneous positive comovements in revenues, leave regional deficits unchanged and generate negative comovements in regional output. These dynamics are standard in general equilibrium models of fiscal policy. For example, Baxter and King (1993) and Ohanian (1997) showed that in a RBC type model an increase in government spending, financed through labor taxation, temporarily decreases consumption and investment and has protracted negative output effects. While the sign of the output effect is robust across models with different microfundations, the magnitude of the fall depends on the source of financing (e.g. income taxes vs. sales taxes), on the elasticity of labor and capital supply to distortionary taxes and on whether a balance budget is imposed on a period-by-period basis or if some flexibility is allowed. Since the timing of the output responses is unrestricted, anticipatory effects are not a-priori ruled out, as are not ruled out future increases in distorting taxation of the type considered by, e.g., Dotsey (1994).

For revenue disturbances, we seek shocks with the following features:

- (T shocks) They produce contemporaneous negative comovements in regional deficits and negative comovements in regional output.

The revenue disturbance we concentrate on is again standard (see e.g. Fatas and Mihov (2001)). An unexpected decrease in tax revenues increases local deficits and stimulates output by reducing the tax burden on the local economy. Here government expenditure is NOT assumed to be unchanged: in fact, it could negatively comove with output if government consumption partially plays an automatic stabilizer role. What is crucial for identification is that the comovements of expenditure and taxes are low so that budget deficit negatively comove with revenue disturbances. Also for these shocks the timing of output responses is unrestricted ${ }^{3}$.

\footnotetext{
${ }^{3}$ In a earlier version of the paper we have also searched for "Reagan-Laffer" shocks. Whenever distortionary taxation is high, a decrease in tax revenues (engineered via a decline in average or marginal tax rates) may stimulate
} 
We summarize the identifying restrictions in table 1. Since no restrictions are placed on price differentials, we are in the position to examine their dynamic behavior in response to fiscal shocks.

Table 1: Identification Restrictions

\begin{tabular}{|c|c|c|c|c|c|}
\hline & $\operatorname{Corr}(\mathrm{G}, \mathrm{Y})$ & Corr $(\mathrm{T}, \mathrm{Y})$ & Corr (G, Def) & $\operatorname{Corr}(\mathrm{T}$, Def $)$ & $\operatorname{Corr}(\mathrm{G}, \mathrm{T})$ \\
\hline G shocks & $>0$ & & $>0$ & & $>0$ \\
\hline BB shocks & $<0$ & & $=0$ & & $=1$ \\
\hline $\mathrm{T}$ shocks & & $<0$ & & $<0$ & $=0$ \\
\hline
\end{tabular}

Since our approach to identification differs from the one typically used in the literature, it is useful to highlight major differences and the advantages of our strategy. The existing literature typically uses case study approaches, extraneous information or zero restrictions on the contemporaneous covariance matrix of VAR residuals to disentangle fiscal shocks from reduced form innovations. Case studies (see Ramey and Shapiro (1998) or Burnside, Eichenbaum and Fisher (2002)) are powerful way to study fiscal policy whenever one can make sure that the fiscal change is truly exogenous. As argued in Perotti (2002), such an assumption is problematic in at least two of the three typically studied episodes (Korean War, Vietnam war, Reagan buildup). Relative to standard identification approaches, our restrictions are theory based, while those employed in the literature are, to a large extent, conventional and hard to justify with low frequency data. For example, assuming that tax revenues do not respond to expenditure shocks within a period - an assumption used in the literature to disentangle revenue and tax shocks - is problematic with annual data. Similarly, the restrictions needed to identify expenditure shocks in quarterly data - e.g. that it takes more than a quarter for government spending to respond to unexpected output movements (Blanchard and Perotti (2002)) - are unappealing in annual data because of the presence of automatic stabilizers. Since our methodology does not make use of zero restrictions, both the endogeneity which plagues exercises where delay restrictions are used and the inherent underidentification which results from the general equilibrium nature of fiscal shocks are resolved.

To recover shocks with the required characteristics we use the methodology of Canova and De Nicoló (2002). The approach starts from the eigenvalue-eigenvector orthogonalization of the variance covariance matrix of VAR residuals and proceeds examining the responses of the endogenous variables to each of the orthogonalized shocks. If we are unable to simultaneously find revenue and expenditure shocks producing the required comovements in the variables, the

output to such an extent that the initial cut in revenue is more than compensated by the larger tax base over which the lower tax applies. Consequently, deficits may be left unchanged or even decrease. Shocks with these characteristics appear to be absent from both the data sets we examine. 
eigenvalue-eigenvector decomposition is rotated by an orthonormal matrix $P(\theta)$, where $\theta$ measures the angle of rotation, and the comovements in response to the new set of shocks examined. This search process continues, varying $\theta$ in the range $(0, \pi)$ and the columns of $P(\theta)$ which are rotated. Many $P(\theta)$ can in principle produce the pattern we look for. The standard errors attached to point estimates not only reflect uncertainty surrounding reduced form parameter estimates but also how individual responses vary with these $\theta$ 's and $P$ 's. Since the methodology allows us to thoroughly search the space of identification, one can examine whether the restrictions imposed are meaningful or vacuous. Appendix B summarizes the algorithm used in the search.

\section{Combining the information from different units}

Since both data sets are short, structural responses are likely to be imprecisely estimated. One way to improve their quality is to construct an estimate which efficiently combines unit specific and cross sectional information. In addition, if some extra-sample information is available, one could combine the two types of information to construct "improved" estimates of the dynamics of interest. We use both ideas in this paper. For the US we use cross unit information to construct a posterior estimator of the structural price differential responses which endogenously weights unit specific and average cross sectional information with their relative precision. This estimator collapses to a standard OLS estimator, unit by unit, when there is no information in the cross section, and to a pooled estimator when the cross sectional information dominates. On the other hand, we use the posterior distribution for US responses to "calibrate" the prior for structural price differential responses in the EMU. Posterior price differential responses will then contain this prior information and the unit specific information, weighted by their relative precision.

Let the five variable $\operatorname{VAR}(\mathrm{p})$ for each unit $i=1, \ldots N$ be written in a companion form $Z_{i t}=$ $A_{i} Z_{i t-1}+B_{i} W_{t}+U_{i t}$, where $W_{t}$ includes all exogenous variables, $Z_{t}$ is a $5 p \times 1$ vector containing, stacked, the $p$ lags of each of the variables of the model, $A_{i}$ is $5 p \times 5 p$ and $U_{i t} \sim\left(0, \Sigma_{i}\right)$. Let the structural moving average (MA) representation for the system be

$$
X_{i t} \equiv Z_{i t}-A_{i}^{t} Z_{i 0}-B_{i} \sum_{j=0}^{t-1} A_{i}^{j} W_{t-j}=\sum_{j=0}^{t-1} C_{i}^{j} E_{i t-j}
$$

where $C_{i}^{j}=A_{i}^{j} P_{i}(\theta), E_{i t}=P_{i}(\theta)^{\prime} D_{i} U_{i t}$, some $P_{i}(\theta)$ with $P_{i}(\theta) P_{i}(\theta)^{\prime}=I$ and $D_{i}^{\prime} D_{i}=\Sigma_{i}^{-1}$. Let $\alpha_{i}$ be a $25 p^{2}(J+1) \times 1$ vector, each $i$ containing, stacked, the coefficients $C_{i}^{j}$ for horizons ranging from 0 to $J \leq t-1$. We assume that $\alpha_{i}$ are related across $i$ according to the following unit invariant 
specification:

$$
\alpha_{i}=\mu+v_{i} \quad v_{i} \sim N(0, \tau)
$$

where $\mu$ represents the vector of (cross sectional) average structural MA coefficients and $\tau$ its dispersion. Our interest is in producing the posterior of a subset of the $\mu$, the average price differential responses to shocks, and of a subset of the $\alpha_{i}$, the unit specific price differential response to shocks, in describing their features and in highlighting cross sectional differences.

For both monetary unions we assume that $U_{i t}$ are normally distributed and that $\Sigma_{u_{i}}$ has an inverted Wishart distribution with scale $S$ and $\nu$ degrees of freedom. For US states we assume a diffuse prior on $\mu$, so that there is little information about the location of the structural MA coefficients for each unit, treat $\tau$ as fixed and set it equal to $\tau_{j}=\frac{0.2}{j}, j=0,1, \ldots, J$, which allows for considerable difference in individual units structural responses for the initial periods. For EMU countries we assume that the a-priori distribution of $\mu$ is proportional to the posterior distribution obtained for US states and set $\tau_{j}=\frac{0.2}{j}, j=0,1, \ldots, J$. Since the two data sets come at different frequencies, we take the prior mean for $\mu$ in EMU countries at the quarterly frequency to be one-fourth of the US posterior mean for $\mu$ at the annual frequency and the prior quarterly standard deviation of $\mu$ to be a half of the annual US posterior standard deviation of $\mu$. These two assumptions imply that the annual prior for the vector of average structural response in the EMU is centered around the annual posterior mean of the average US structural responses but has a larger variance.

The MA representation (1), the prior structure (2) and the assumptions made imply that, in both cases, the joint posterior distribution for $\left(\alpha_{i}, \mu, \Sigma_{u_{i}}\right)$ has a Normal-Wishart structure. In particular, $\left(\alpha_{i} \mid \mu, \tau, \Sigma_{u_{i}}, Z\right), \sim N\left(\tilde{\alpha}_{i}, \tilde{V}_{\alpha}\right)$, where $\tilde{\alpha}_{i}=\tilde{V}_{\alpha_{i}}\left(\hat{V}_{\alpha_{i}}^{-1} \hat{\alpha}_{i}+\tau^{-1} \mu\right)$ and $\tilde{V}_{\alpha}=\left(\hat{V}_{\alpha_{i}}^{-1}+\tau^{-1}\right)^{-1}$; $\hat{\alpha}_{i}$ is the unit specific OLS estimator of $\alpha_{i}$ and $\hat{V}_{\alpha_{i}}$ its covariance matrix. Hence, $\tilde{\alpha}_{i}$ is a weighted average of the prior mean $\mu$ and the OLS estimate of $\hat{\alpha}_{i}$ with weights given by the inverse of their variances (precision). For US states $\left(\mu \mid \tau, \Sigma_{u_{i}}, Z\right) \sim N\left(\tilde{\mu}, \tilde{V}_{\mu}\right)$ where $\tilde{\mu}=\tilde{V}_{\mu}\left(\sum_{i}^{N}\left(\hat{V}_{\alpha_{i}}+\tau\right)^{-1} \hat{\alpha}_{i}\right)$ and $\tilde{V}_{\mu}=\sum_{i}^{N}\left(\hat{V}_{\alpha_{i}}+\tau\right)^{-1}$. Therefore, the posterior mean of $\mu$ is a weighted average of OLS estimates with weights given by precision of the estimates. For EMU countries the posterior distribution for $\mu$ has mean equal to $\tilde{\mu}=\tilde{V}_{\mu}\left(\sigma_{\mu}^{-1} \bar{\mu}+\sum_{i}^{N}\left(\hat{V}_{\alpha_{i}}+\tau\right)^{-1} \hat{\alpha}_{i}\right)$ and variance $\tilde{V}_{\mu}=\left(\sigma_{\mu}\right)^{-1}+\sum_{i}^{N}\left(\hat{V}_{\alpha_{i}}+\tau\right)^{-1}$ where $\bar{\mu}$ and $\sigma_{\mu}$ are the moments of the prior distribution of $\mu$. Finally, $\left(\Sigma_{u_{i}} \mid \tau, Z\right), \sim I W(S+$ $\left(X_{i} X_{i}^{\prime}, T+\nu\right)$ where $X_{i}$ is obtained stacking the $T$ observations for $X_{i t}$ and IW stands for inverted Wishart.

Note that since the posterior distributions of components of $\mu$ and $\alpha_{i}$ are normal, the posterior 
means $\left(\tilde{\mu}, \tilde{\alpha}_{i}\right)$ can be used as point estimates and the posterior $68 \%$ range as a measure of the uncertainty surrounding structural price differential responses. Finally, since we simultaneously identify revenue and expenditure shocks and since the identified shocks are orthogonal both among themselves and to the block of non-identified disturbances by construction, standard summary statistics (e.g. variance decomposition) can be directly computed and interpreted from posterior estimates and the identified shocks.

\section{The Results}

\subsection{Benchmarking the shocks}

The identification of structural shocks was partially successful. While in most US states and EMU countries we were able to obtain $\mathrm{G}$ and $\mathrm{T}$ shocks, we managed to recover balance budget shocks only in a few US states. Two facts may account for our failure: first, several US states use funds external to the yearly budget (e.g. stabilization funds) to smooth out those revenue fluctuations that would otherwise require changes in expenditure to maintain a balance budget; second, EMU data is short and Maastricht restrictions were not binding for most of the sample.

For the US, we identify G shocks in 36 states, BB shocks in 12 states and T shocks in 31 states while for the EMU we identify $\mathrm{G}$ shocks in 8 countries and $\mathrm{T}$ shocks in 5 countries. Since our methodology is novel, it is important to make sure that the shocks we recover have reasonable features. Since the literature concentrates on output multipliers and since numerous estimates in response to tax and expenditure shocks are available for both the US and the major EMU countries, we examine the reasonableness of our estimates using this metric. Output multipliers are computed here as the ratio of the output response to the fiscal shock scaled by the fiscal variable as percentage of GDP, as in Mountford and Uhlig (2002). Since yearly multipliers are typically reported we focus on instantaneous multipliers when discussing US data, while we cumulate the effect to the yearly frequency when discussing EMU data. Given the size and the shape of the responses, cumulating the effect say, to 4 years, would change little in the qualitative features of the results we present.

In the US two-third of the G shocks produce output multipliers above one, the median value equals 1.40 and the interquartile range is $[0.98,2.54]$. The 11 states whose output multiplier is less than one are typically small (e.g. New Hampshire and Maine) or located in the Midwest (e.g. Kansas or Illinois). Output multipliers are smaller following T shocks suggesting that deficit financed expenditure shocks crowd out either consumption or investment less than deficit financed 
tax cuts. In fact, there are 17 states for which multipliers are less than one; the median value is 0.72 and the interquartile range is [0.43, 3.00]. Blanchard and Perotti (2002) using aggregate quarterly US data, more standard VAR techniques and a different definition, find yearly multipliers smaller than our median values, but have revenue multipliers which are almost twice as large as expenditure multipliers. One reason for the smaller relative size of our revenue multipliers is the fact that local taxes are only a small percentage of the total tax burden of the resident of a US state. Therefore, their multiplicative effects are likely to be smaller. For comparison, we have used our technique on yearly aggregated US data and found that the yearly output multipliers to G and T shocks are, respectively, 0.55 and 0.86, roughly the same as Blanchard and Perotti. On the other hand, traditional multi-equation models, see e.g. Bryant et. al. (1993) or Daalgard et. al.(2001), appear to produce output multipliers in response to $\mathrm{G}$ shocks which range from 0.9 to 2.0 , depending on the assumed monetary policy stance, numbers which square well with our interquartile range estimate for $\mathrm{G}$ shocks.

Table 2: Yearly Output and Employment Multipliers

\begin{tabular}{l|ccc|ccc|}
\hline \hline & \multicolumn{3}{|c|}{ Output } & \multicolumn{3}{c|}{ Employment } \\
\hline & G shocks & BB shocks & T shocks & G shocks & BB shocks & T shocks \\
\hline & \multicolumn{5}{|c|}{ US states } \\
\hline Median & $1.40(\mathrm{TX})$ & $-3.78(\mathrm{NJ})$ & $0.72(\mathrm{CT})$ & $0.03(\mathrm{OR})$ & $-0.15(\mathrm{WA})$ & $0.05(\mathrm{ME})$ \\
Min & $0.26(\mathrm{NH})$ & $-34.69(\mathrm{KS})$ & $0.001(\mathrm{CO})$ & $-0.11(\mathrm{ND})$ & $-0.39(\mathrm{UT})$ & $-0.08(\mathrm{MI})$ \\
Max & $23.60(\mathrm{NM})$ & $-0.10(\mathrm{PA})$ & $11.10(\mathrm{TN})$ & $0.28(\mathrm{WV})$ & $0.17(\mathrm{NJ})$ & $0.27(\mathrm{WA})$ \\
$25 \%$ & $0.98(\mathrm{AZ})$ & $-14.44(\mathrm{UT})$ & $0.43(\mathrm{NB})$ & $0.02(\mathrm{MI})$ & $-0.30(\mathrm{SC})$ & $0.01(\mathrm{IN})$ \\
$75 \%$ & $2.54(\mathrm{NC})$ & $-1.50(\mathrm{MT})$ & $3.00(\mathrm{NV})$ & $0.08(\mathrm{SD} 0$ & $0.01(\mathrm{PA})$ & $0.06(\mathrm{GA})$ \\
\hline & \multicolumn{5}{|c|}{ EMU countries } \\
\hline Median & $0.79(\mathrm{IR})$ & $0.60(\mathrm{ES})$ & $-0.19(\mathrm{ES})$ & $0.08(\mathrm{ES})$ \\
Min & $0.25(\mathrm{GE})$ & $0.13(\mathrm{GE})$ & $-1.73(\mathrm{BE})$ & $-0.08(\mathrm{FR})$ \\
Max & $6.30(\mathrm{BE})$ & $9.20(\mathrm{IR})$ & $4.89(\mathrm{FI})$ & $1.06(\mathrm{IT})$ \\
\hline \hline
\end{tabular}

Interestingly, labor productivity instantaneously increases in 21 states following $\mathrm{G}$ shocks and in 26 states following $\mathrm{T}$ shocks. In competitive labor markets this increase in productivity will be translated in increases in real wages. Since production costs are likely to be higher, and since the increase is typically larger for tax shocks, the production costs channel may also be a reason for the small output multipliers produced by revenue shocks.

The output multipliers generated by a balance budget shocks are typically large. In fact, in 10 of the 12 cases the multiplier exceeds -1.0 , in six it exceeds -5.0 and the median value is -3.78 . These numbers are comparable to those produced by Baxter and King (1993) in a RBC model where labor supply is elastic: their estimate, using calibrated parameters, is -2.5. 
In the EMU, output multipliers are larger than one in 3 cases for $\mathrm{G}$ shocks (with median annual response equal to 0.79 ) and in 3 cases for $\mathrm{T}$ shocks (with median annual response 0.60). These numbers are smaller than those that Perotti (2002) reports for 5 OECD countries using different identification strategies, a different definition and a much larger sample size, but comparable to those presented by Roeger and in't Veld (2002), and by Hunt and Laxton (2002), who use traditional structural models for Italy, France and Germany, and by Hernadez de Cos et. al. (2003), who used a variety of Euro area Central Bank's models and the Area wide model of the ECB - the range of yearly output multipliers to $\mathrm{G}$ shocks is between 0.47 and 1.37 .

In general, three features of EMU multipliers to fiscal shocks need to be emphasized. When compared with US states, output multipliers in response to tax shocks are somewhat larger, reflecting the relative importance of revenues in total GDP. Clear exceptions are the Netherlands and Germany where multipliers are small. Second, expenditure shocks produce employment multipliers which are smaller, in general, in the EMU. Hence, expenditure increases are a much more powerful employment lever in US states than EMU nations. Third, expenditure shocks increase productivity in all EMU countries but Finland, and the average size of the increase is larger than in US states. We conjecture that different labor market institutions may account for the relative size of output and productivity multipliers in the two unions.

As a further check on the reasonableness of our approach we have examined whether our US fiscal shocks contain some endogenous component by regressing them on a few local, regional and aggregate indicators (local unemployment, regional GDP and aggregate M1). Overall, our fiscal shocks do not appear to proxy for omitted variables.

\subsection{Average Effects}

In all the figures we present below, we normalize the expenditure impulse to be positive and of unitary size and the revenue impulse to be negative and of unitary size.

\subsubsection{The United States}

Figure 1 reports the cross sectional average response of price differentials (column 1), of employment differentials (column 2), and of output differentials (column 3) to the three types of disturbances. Each box plots the posterior mean and a central 68 percent posterior range. 

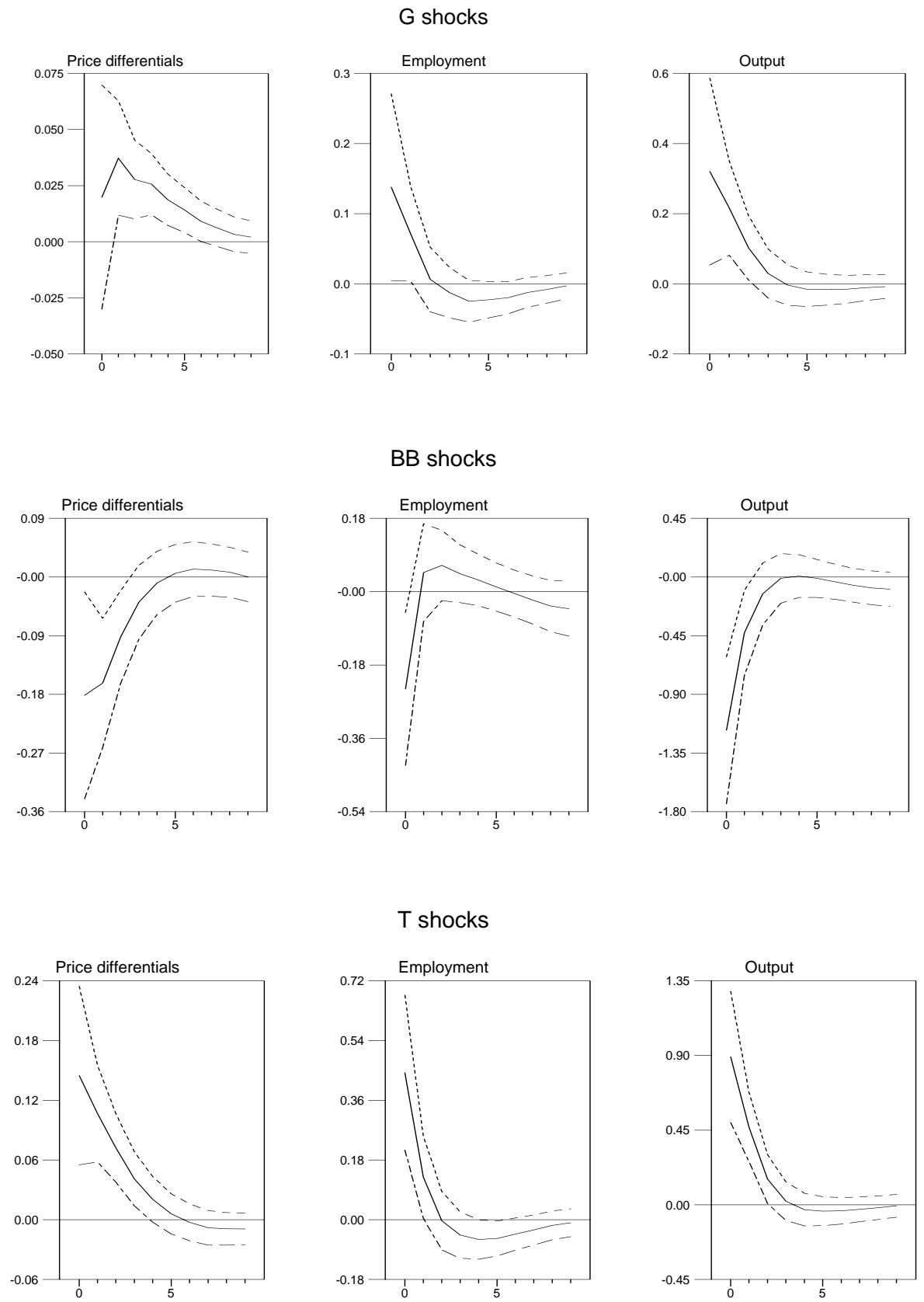

Figure 1: Average responses in the US

On average, $\mathrm{G}$ and $\mathrm{T}$ disturbances significantly increase price differentials. Recall that our identification requires these shocks to increase output and deficits. Standard textbook analysis suggests that following the fiscal expansion the local demand curve moves to the right. Whenever 
local demand is biased toward locally produced goods, which appears to be the case on average, given the responses of relative employment, local prices increase more than union wide prices.

A BB type disturbance significantly decreases price differentials on average. Such a pattern can be easily interpreted recalling the identification restrictions. An expenditure increase, financed by distortionary taxation, is in fact assumed to have contractionary effects on output. Therefore, although the increase in government spending may shift local demand to the right, the increase in distortionary taxation needed to maintain a balanced budget, shifts the same curve to the left. As a result, both relative output and relative employment fall and price differentials decrease.

Note that, while price differential responses are contemporaneously significantly different from zero for BB and $\mathrm{T}$ shocks, it takes about a year for $\mathrm{G}$ shocks to exercise a statistically significant effect. Furthermore, while for the first two shocks significant price differentials responses are noticeable for up to 2-3 years, in the latter case, responses become insignificant again only after 6 years. Hence, G shocks take time on average to spill onto prices but their effect is more persistent. One may be tempted to interpret this evidence as indicating that price stickiness differs in response to different shocks. This is incorrect: since standard errors are relatively large even in the initial period, it is impossible to identify the timing of the peak response with absolute precision.

The magnitude of the responses differs across types of shocks. In fact, the mean of the posterior price differential response is -0.18 percentage points in the case of $\mathrm{BB}$ shocks; 0.15 in the case of $\mathrm{T}$ shocks and a mere 0.025 percent in the case of $\mathrm{G}$ shocks. This ordering of magnitudes is in line with the ordering of relative output and relative employment responses to the three shocks and with the findings of Mountford and Uhlig (2002) for aggregate data.

\subsubsection{The EMU}

Price differential responses for the EMU are also in line with theoretical expectations: both G and $\mathrm{T}$ disturbances increase, on average, price differentials. The effect lasts longer for $\mathrm{G}$ shocks (5 quarters) than for $\mathrm{T}$ shocks (1 quarter) and, contrary to what we have documented for the US, responses peak instantaneously in both cases.

The magnitude of the mean of the posterior response of price differentials to $\mathrm{G}$ disturbances is 0.18 and to T shocks is about 0.12 . Therefore, contrary to what we have found in US states, expenditure shocks have larger effects on price differential than revenue shocks. This difference has to do with the size of government consumption expenditure to output ratio, which is more than twice as large on average in the typical EMU country as in a US state (0.21 to 0.09). 

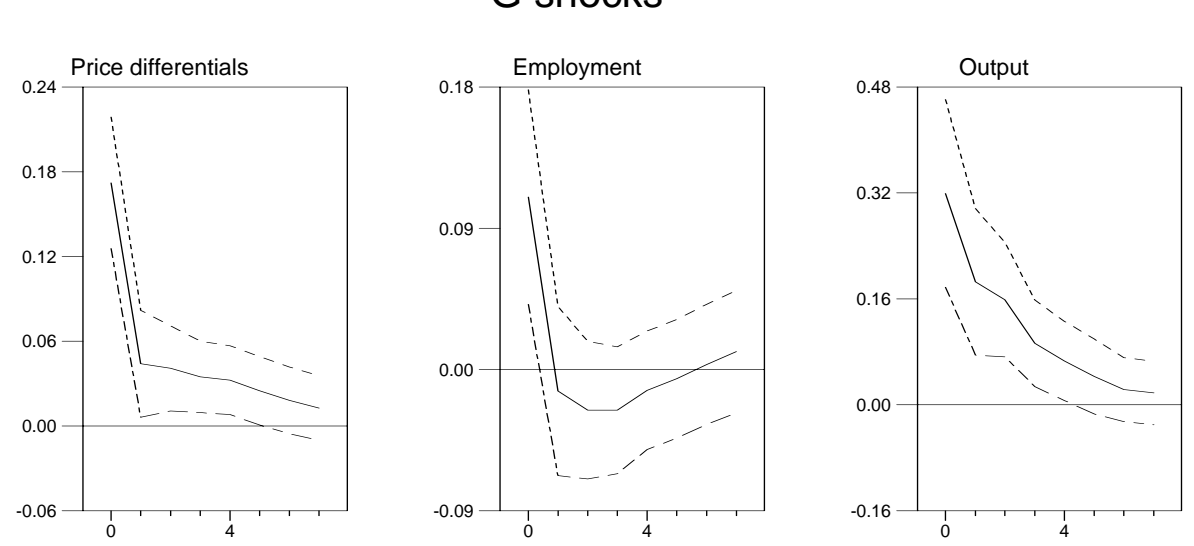

T shocks
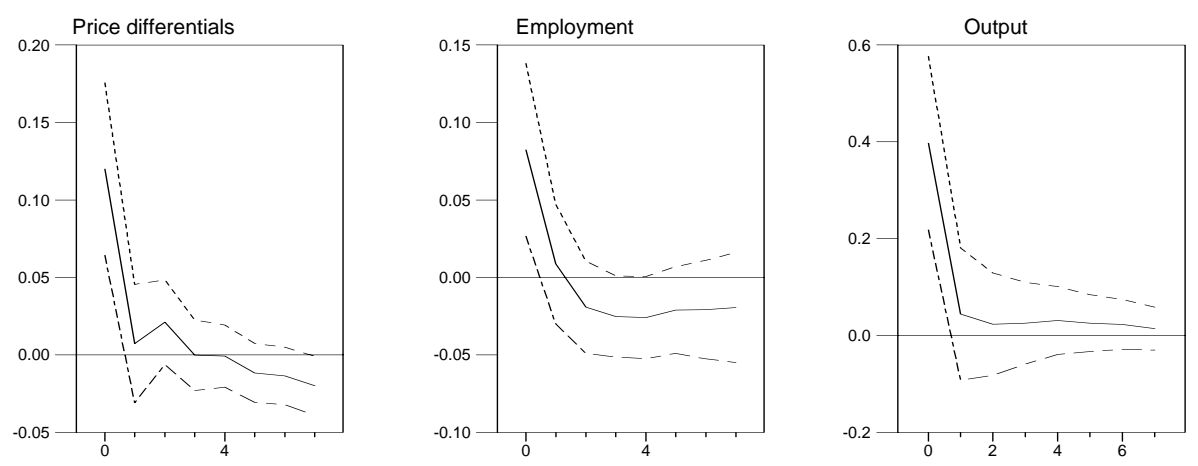

Figure 2: Average Responses in EMU

Recall that estimates of structural responses in the EMU are obtained under the assumption that, a-priori, the distribution of the vector of average structural responses, is similar to the posterior distribution of average responses of US states. Although qualitatively similar, price differential responses are quantitatively different in the two areas. Hence, despite the short sample, there is information in the data to pull the posterior away from the prior.

To summarize, fiscal disturbances which expand output and deficit increase price differentials (either instantaneously or with a lag) while disturbances which contract output and leave deficit unchanged decrease price differentials. The size and the timing of the effects vary with the type of disturbances and the monetary union. In the US balance budget disturbances are the most effective in altering price differentials on average; expenditure shocks impart the most persistent responses and revenue shocks the most similar dynamics across states. In the EMU, the pattern induced by 
expenditure and revenue shocks is similar.

\subsection{Individual unit pattern}

While average price differential responses are in line with theoretical expectations and the predictions of existing large scale macro models (see Hernandez de Cos, et. al. (2003)), there are important heterogeneities in the signs, the shapes and the magnitude of the responses of individual units in both monetary unions.

Since the reader may not be aware of the consequences that our stochastic pooling procedure has on structural responses for each unit, we briefly discuss the differences obtained using single unit and cross sectional information. In Figure 3 we present estimates of price differential responses in two states for each of the three shocks: the top row reports cases where differences are visible, the bottom row cases where they are not.

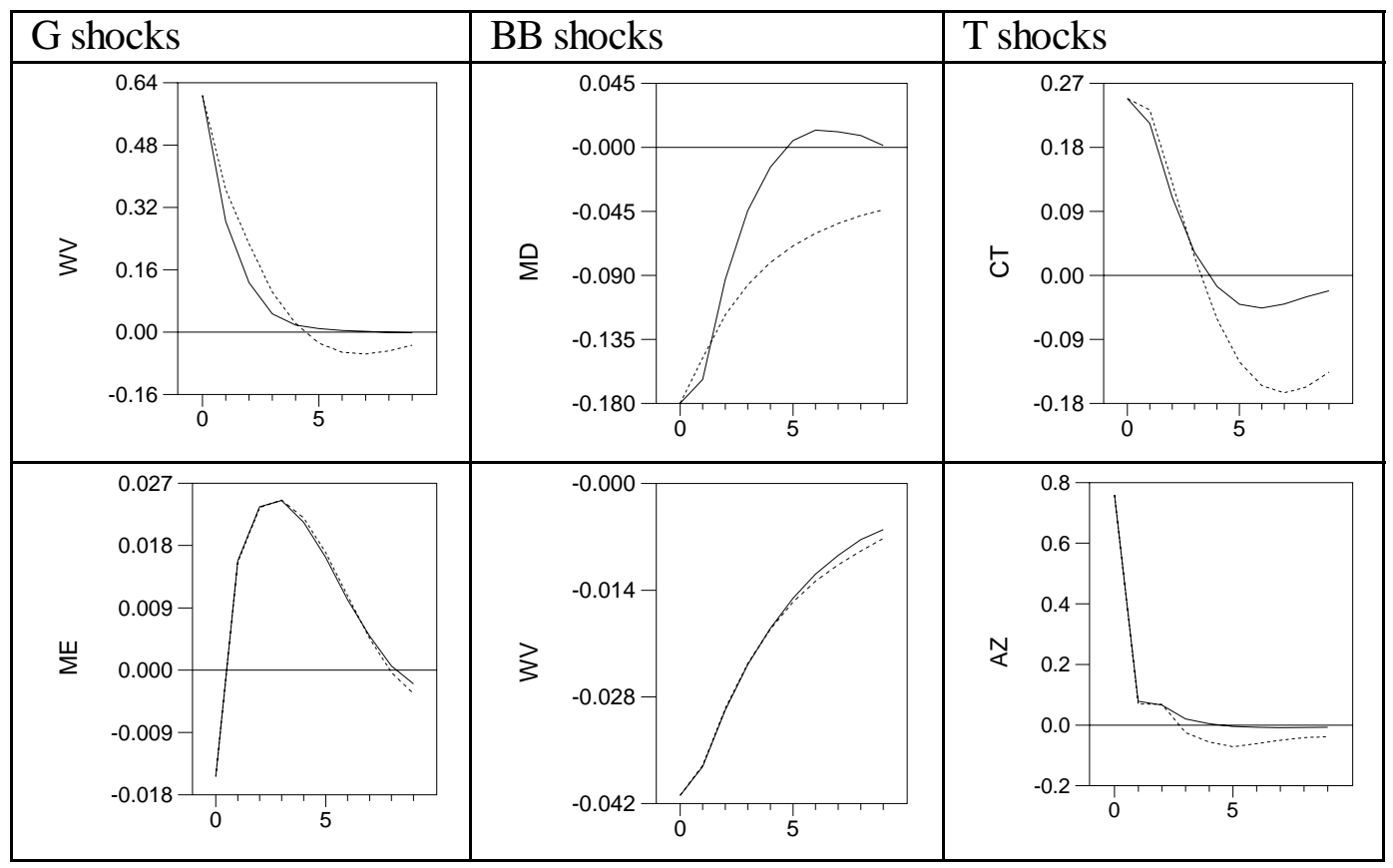

Figure 3: OLS and Posterior estimates

Overall, estimates differ primarily in the medium-long run. For example, the responses of price differentials in West Virginia (to a G shock), Maryland (to a BB shock) and Connecticut (to a $\mathrm{T}$ shock) tend to be highly persistent and the latter two are still far away dying out 10 years after the shocks when individual state data is used (dotted line). Such a pattern disappears, or 
is considerably reduced, when cross sectional information is taken into account (straight line). In general, the use of cross sectional information does not change either the shape or the timing of the structural responses but affects the persistence of price differential dynamics.

\subsubsection{US States}

Price differential responses in US states are somewhat heterogenous ${ }^{4}$. For example, in 6 out of 36 cases the peak response to $\mathrm{G}$ shocks is instantaneous while in the remaining 29 a hump response is obtained (with the peak occurring between 2 and 5 years). In addition, in 5 states the response is never significant, while in 7 is significant for up to 5 years. For those 31 states displaying significant price differential responses for at least one period, the absolute size of the maximum response varies from -0.09 to 0.61 (with the median around zero). For T shocks the pattern is similar. Price differential responses have a hump in 13 of the 31 cases and the peak response also varies between 2 and 5 years. There are 8 states for which responses are significant only for one year and 5 for which responses are significant for at least 5 years; and the absolute size of maximum response varies from -0.60 to 0.86 . For BB shocks, price differential responses have a hump in 10 cases, the location of the hump varies from one to six years and the mean response turns positive at horizons varying from one to five years. Responses die out after one year in six states while in West Virginia price differential responses are significant up to 5 years after the shock. Here, the size of the hump varies from 0.05 to 0.20 and the median is around 0.12. Despite these quantitative difference, several common qualitative features remain: price differential responses to BB shocks are typically larger than those to T or G shocks; G shocks produce lagged and more persistent responses than T shocks.

Table 3: Price Differential responses

\begin{tabular}{|l|ccc|cc|}
\hline \hline & \multicolumn{3}{|c|}{ US states } & \multicolumn{2}{c|}{ EMU countries } \\
\hline & G shocks & BB shocks & T shocks & G shocks & T shocks \\
\hline Median & $0.001(\mathrm{NC})$ & $-0.18(\mathrm{MD})$ & $0.05(\mathrm{WI})$ & $0.01(\mathrm{IT})$ & $0.10(\mathrm{ES})$ \\
Min & $-0.09(\mathrm{AZ})$ & $-0.58(\mathrm{NJ})$ & $-0.60(\mathrm{ME})$ & $-0.09(\mathrm{GE})$ & $0.06(\mathrm{GE})$ \\
Max & $0.61(\mathrm{WV})$ & $-0.02(\mathrm{MT})$ & $0.86(\mathrm{TN})$ & $3.66(\mathrm{BE})$ & $0.28(\mathrm{IT})$ \\
$25 \%$ & $-0.03(\mathrm{SD})$ & $-0.26(\mathrm{MS})$ & $-0.01(\mathrm{IA})$ & & \\
$75 \%$ & $0.03(\mathrm{AL})$ & $-0.04(\mathrm{VW})$ & $0.25(\mathrm{DE})$ & & \\
\hline \hline
\end{tabular}

The most interesting cross state difference in price differential dynamics concerns the sign of the responses to $\mathrm{G}$ and $\mathrm{T}$ shocks (see table 3 ). In fact, in about 35 percent of the states price differential responses to $\mathrm{G}$ shocks are instantaneously negative while $\mathrm{T}$ shocks produce instantaneously

\footnotetext{
${ }^{4}$ Plots of the posterior distribution of price differential responses for each US state and each EMU country to the shocks together with state informations are contained in a technical appendix available on request.
} 
negative price differential responses in about 25 percent of the states. There are asymmetries in the magnitude of price differential responses of the two groups: positive responses are typically larger than negative ones but some large negative price differential movements are present, e.g. in Maine. Interestingly, only in 13 states expenditure increases and revenue cuts move price differentials in the same direction- increases occur in 12 states and decreases in one - and in these states an unexpected reduction in tax revenues produces larger price differential responses than an unexpected expenditure increase.

Table 4: Variance Decomposition

\begin{tabular}{|l|ccc|ccc|}
\hline \hline & \multicolumn{4}{|c|}{$\begin{array}{c}\text { US states } \\
10 \text { year horizon }\end{array}$} & \multicolumn{3}{c|}{$\begin{array}{c}\text { EMU countries } \\
8 \text { quarters horizon }\end{array}$} \\
\hline & \multicolumn{4}{|c|}{ Mean Median Interquartile range } & Mean Median Min-Max \\
\hline G Shocks & 0.14 & 0.11 & {$[0.05,0.17]$} & 0.21 & 0.18 & {$[0.03,0.47]$} \\
BB Shocks & 0.23 & 0.21 & {$[0.10,0.30]$} & & & \\
T Shocks & 0.19 & 0.14 & {$[0.05,0.20]$} & 0.15 & 0.14 & {$[0.03,0.34]$} \\
\hline \hline
\end{tabular}

Central Banks worrying about regional inflation differentials and their potential effects on price stability may be interested in knowing how important are the shocks we have identified in quantitatively explaining price differential variability. Table 4 presents this information at the 10 years horizon: we report the mean, the median and the interquartile range across US states (min-max for EMU) of the price differential movements explained by the three types of shocks. On average, expenditure shocks explain 14 percent, balance budget shocks 23 percent and revenue shocks about 19 percent of price differential variability. For some states the percentage of price differential variability explained is large. In fact, expenditure disturbances in New Mexico and Texas and revenue disturbances in New Hampshire and Tennessee account for 40 percent or more of the variability of local to union wide prices. These large numbers do not appear to be due the result of measurement errors - using implicit price deflator data produced the same result - and could be related to the fact the composition of local output is tilted toward one sector.

Hence, fiscal disturbance can significantly affect price differential variability. In the majority of the cases the contribution is modest, but there are instances where fiscal disturbances are a powerful lever for price differential fluctuations.

\subsubsection{EMU Countries}

Price differential responses to G shocks are heterogeneous also in the EMU. For example, in three countries responses peak instantaneously and in five a hump with location varying from 1 to 5 
quarters occurs; responses are significant for one quarter in Austria and last up to 8 quarters in Italy; the maximum size of the responses varies from -0.09 (Germany) to 3.61 in Belgium. Response to revenue shocks are more similar in shape (they all peak instantaneously) and persistence (they die out after two quarters) but the magnitude of the peak response varies from 0.06 (Germany) to 0.28 (Italy). Also in the EMU there are three countries where expansionary expenditure shocks decrease price differentials. The effect is typically temporary: in Germany it lasts two periods, in Ireland and Spain only one period.

It is worth relating price differential responses to one particular episode which has attracted attention in the policy circles. To induce foreign investments into the country, the Irish government reduced taxes on capital income in the third quarter of 1999 and this led to a significant increase in output in 2000 and the first half of 2001. In February 2001 the European Council issued a warning (Action against Ireland, Euro Official Journal, 9/3/2001, C077, pp.7) calling Irish authorities to restraint their attempts to reduce the cyclically adjusted surplus. In particular, the Council was concerned with the effects that such policy had on inflation differential. Our investigation suggests that such a worry was probably excessive. In fact, the maximum price differential response is "only" 0.25 and occurs in conjuction with a huge expansionary output effect (instantaneous output response is around 7.0). Interestingly, such a number is much larger than the magnitude of price differential responses produced in Germany (maximum about 0.07) or France (maximum 0.09), two countries close to be violating the Growth and Stability Pact limits in the sample.

The percentage of price differential variability explained by fiscal disturbances in EMU countries is qualitatively similar to what we have found for US states. Expenditure shocks account on average for 21 percent and revenue shocks for 14 percent of price differential variability. Heterogeneities are clearly noticeable here: $\mathrm{G}$ shocks explain more than 40 percent of the variability of price differentials in Ireland and Finland and roughly zero in Germany or Spain, while tax shocks explain about 34 percent of price differential variability in Spain and negligible amounts in Belgium, France and Germany. Clearly, one should be careful with these estimates: the sample includes almost a full economic cycle but it may not be representative of the typical conditions present in the EMU.

\subsection{Why are price differential responses negative?}

As we have seen, there are a number of US states and three EMU countries where unexpected expansionary fiscal disturbances bring about a significant and at times persistent reduction in local to union wide prices. These responses are surprising from the point of view of economic theory, both 
of Keynesian and neoclassical orientations, because output increases in response to these shocks. This, for example, excludes explanations based on extreme crowding out of other components of aggregate demand or expectational effects of the type emphasized by e.g., Giavazzi, Jappelli and Pagano (2000), since in these episodes local to union wide outputs and prices move in the same direction. Similarly, explanations based on the assumption that fiscal policy may anticipate local recessions and therefore spuriously produce negative price differentials are excluded by our identification scheme which requires output and expenditure to move in the same direction. Note also that when estimating individual effects, we have not restricted the sum of price differential responses to be zero. Therefore, there is no reason to expect that responses will be positive in some units and negative in others. While the pattern is somewhat puzzling, it is by no means uncommon. In fact, when using aggregate US data and different identification strategies, Mountford and Uhlig (2002), CEPS (2002) and Canzoneri, Cumby and Diba (2002) all find that prices decline after either a revenue cut or an expenditure increase, and Perotti (2002) finds that such an effect occurs also in other OECD countries, unless extraneous information is used to pin down the price elasticity of spending disturbances.

To characterize units with a perverse pattern, we have looked at a number of indicators. We examined whether the geographical position of a unit, its economic size (measured by the relative population size or by the relative GDP size), the size of its local government (measured by the average expenditure to GDP or average deficit to average union wide deficit), the magnitude of the government debt (measured by the average debt to GDP) and the state of government finances (measured by the average Moody rating over the period), the composition of output and, for US states, the index of strictness of balance budget requirements (measured by the ACIR index), the political color of the governors and of the state parliaments and the average price of land could be used to characterize states where expansionary fiscal shocks induce negative price differential responses. In general, none of these variables seem to matter. For example, take the US and expenditure shocks. Among, the states with negative price responses, we have both small and large states (e.g. Vermont and Mississippi vs. Michigan or New York); states where the expenditure to GDP ratio is both small and large relative to the average (Illinois vs. Maine); states with good and relative bad credit ratings or high and low average level of debt (e.g. Vermont vs. Arizona); states where the agricultural sector is large and small (e.g. Kansas vs. Michigan); states which were, on average, republican and democrat (e.g. Nevada vs. Vermont); and states where land prices were higher or lower than average (e.g. New York and Wisconsin). While surprising at first, 
this outcome is reasonable: since these indicators capture much longer types of trends, they do not affect the dynamics we care about.

Theoretically, we can think of two possible reasons for why fiscal expansions may induce negative price differential responses. The first has to do with spillover effects: if increases in local demand are spread over a number of units and if multiplier effects pile up, union-wide demand may increase more than local demand and this may make union-wide prices respond more strongly than local prices to unexpected expansionary local fiscal shocks. The second has to do with movements in the local aggregate supply curve: expansionary fiscal shocks may in fact shift such a curve to the right as agents optimally readjust their labor supply and investment decisions. If the magnitude of the movements are right, price differentials may decline.

The composition of tax revenues can also account for the negative responses of price differentials to revenue shocks. In fact, while cuts in income or capital taxations may induce labor (and capital) supply effects in some scenarios, these effects are likely to be small in the case of indirect taxes. Hence, distinguishing between various types of revenues cuts could be important, especially because among US states with negative price differential responses are a few where the fraction of state government activities financed through state income and corporate taxes is higher than average (see table 5).

Table 5: Tax Decomposition, Selected US states

\begin{tabular}{|l|ccc|}
\hline \hline & \multicolumn{3}{|c|}{ ales Tax Income Tax Corporate Tax } \\
\hline $\mathrm{AR}$ & 0.60 & 0.32 & 0.08 \\
$\mathrm{CO}$ & 0.54 & 0.40 & 0.06 \\
$\mathrm{IA}$ & 0.55 & 0.38 & 0.07 \\
$\mathrm{IN}$ & 0.63 & 0.32 & 0.05 \\
$\mathrm{LA}$ & 0.73 & 0.17 & 0.10 \\
$\mathrm{ME}$ & 0.67 & 0.27 & 0.06 \\
$\mathrm{OH}$ & 0.67 & 0.26 & 0.07 \\
$\mathrm{SD}$ & 0.96 & 0.00 & 0.04 \\
\hline US Average & 0.65 & 0.27 & 0.08 \\
\hline \hline
\end{tabular}

Spillover effects may occur for many reasons. For example, it could be that the size of the state is large and the multiplicative effects generated in the region are of an order of magnitude larger than those generated locally or that the difference between local GDP and local GNP is large. We have seen that size does not matter; the GNP/GDP difference is unavailable for US states. Casual empiricism suggests that this difference is larger for North Eastern and Eastern states than for Midwest or Western states, but, again, location does not seem to matter. In the EMU the 
GNP/GDP differential is important for Ireland - on average it was $14 \%$ over the period but it is hardly a factor for Spain or Germany, the other two countries with negative price differential responses. Another possibility is that expansionary fiscal policy may increase the demand of nonlocally produced goods. This could occur, for example, when the industrial structure of a unit has particular features (e.g. value added is skewed toward a particular activity), when the productive structure is such that local output is produced with intermediate inputs coming from neighboring units or when home bias in consumption is small. To effectively examine this hypothesis one needs intrastate and intracountry trade data or the industrial composition of value added in each state (nation). We have managed to find bilateral trade data for EMU countries and found some evidence that trade effects are important. However, the size of trade spillovers, as measured by the instantaneous response of import, is modest, similar to the average EMU effect for Germany and Spain (0.02), and negligible for Ireland.

Lacking bilateral trade data for US states, we check for spillover effects indirectly examining price differential for BLS regions - our working assumption being that spillovers are localized within BLS geographical regions. Therefore, if the hypothesis is correct, regional prices should increase in response to expansionary local fiscal shocks or, at the very least, decrease less.

The results are somewhat supportive of the spillover hypothesis. In 5 of the 16 states where local expenditure shocks reduced local to union wide prices, regional to union wide prices increase and in 4 of the 7 states where local revenue shocks reduced local to union wide prices, regional to union wide prices increase (or decline less than local prices). We present a few typical cases in figure 4. In Arizona and Mississippi, relative prices persistently fall following a G shock, while BLS regional relative prices are significantly increased for about two years. In Arkansas revenue cuts have an initially strong negative impact on local relative prices but regional prices move up significantly. For Maine the effect on New England price differential is qualitatively similar to the one for the state but, quantitatively, the effect is considerably muted.

Dynamic general equilibrium models tell us that changes in the fiscal stance may have important repercussions on the aggregate supply of the economy. First, there is a direct effect due, for example, to the fact that higher spending on infrastructure increases the productivity of factors of production and this, in turns, shifts the aggregate supply. If relative movements in the aggregate demand and the aggregate supply are "right", it is possible that local to union wide prices to countercyclically respond to local fiscal shocks. The second effect is indirect: an increase in government spending might induce an increase in labor supply which, in turns, shifts the aggregate supply curve to the 
right. This could happen, for example, if agents expect the increase in government spending to be financed by future taxation; since agents would be induced to work harder in the current period and intertemporally substitute leisure.

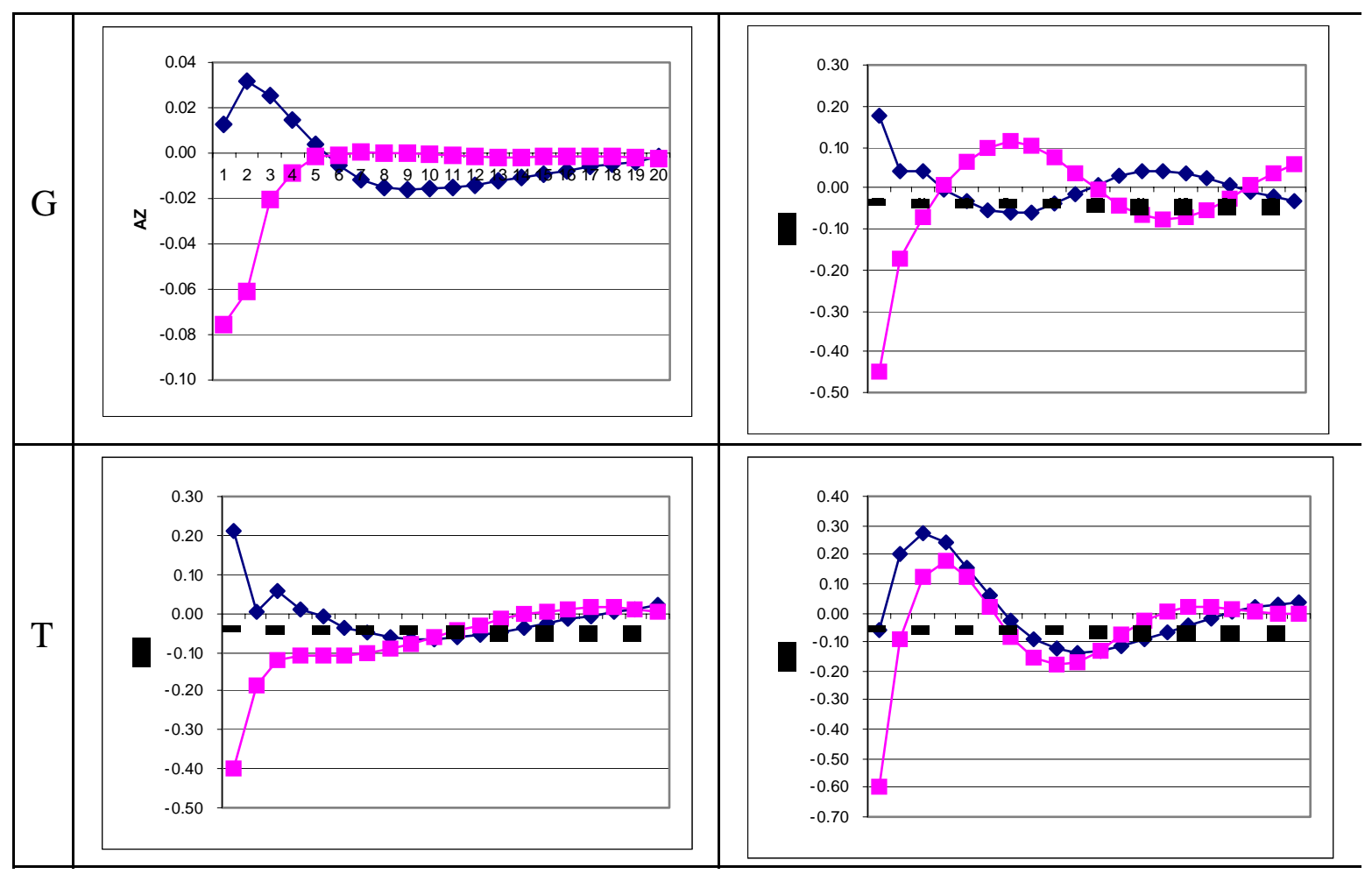

Figure 4: Local Spillover Effects

While intuitively plausible, calibrated analyses of general equilibrium models (e.g. King and Baxter (1993)) have hard time to make this effect non-negligible. In general, if the latter channel is operative, units with falling price differentials should display employment and output responses which are significantly larger than those of units with increasing price differentials.

The evidence on these issues is mixed: in only a few of the US states with negative price differential responses, the output effect is larger than the average (in 3 out of 16 for both expenditure shocks and 2 out of 7 for revenue shocks). Employment responses are slightly more in line with the prediction of theory in the case of expenditure shocks (5 out of 16) but, in general, the effect is minor. In the EMU the output effect for Spain is larger than the average, the Irish one becomes larger after a quarter, while the one for Germany is small. Employment effects are negligible in Germany and negative in Ireland and Spain. 
The composition of tax revenues can also provide important information about local aggregate supply movements. If a revenue cut is engineered via reduction of income taxation, price differentials may fall when the substitution effect is strong and dominates the income effect on agents' labor supply. A decrease in income taxation in fact makes agents wealthier and, as a result, may reduce their labor supply. On the other hand, it also increases the relative price of leisure and may induce agents to work harder. If this second effect dominates, the aggregate supply shifts to the right and prices differentials may fall. If the cut in revenues is engineered via reduction of capital taxes, the marginal product of capital increases, investments become more profitable and therefore consumption may fall. Therefore, cuts in capital taxation may also reduce prices differentials in some scenario. It is however hard to conceive the existence of sizable supply effects when revenue reductions are engineered through cuts in sales taxes ${ }^{5}$.
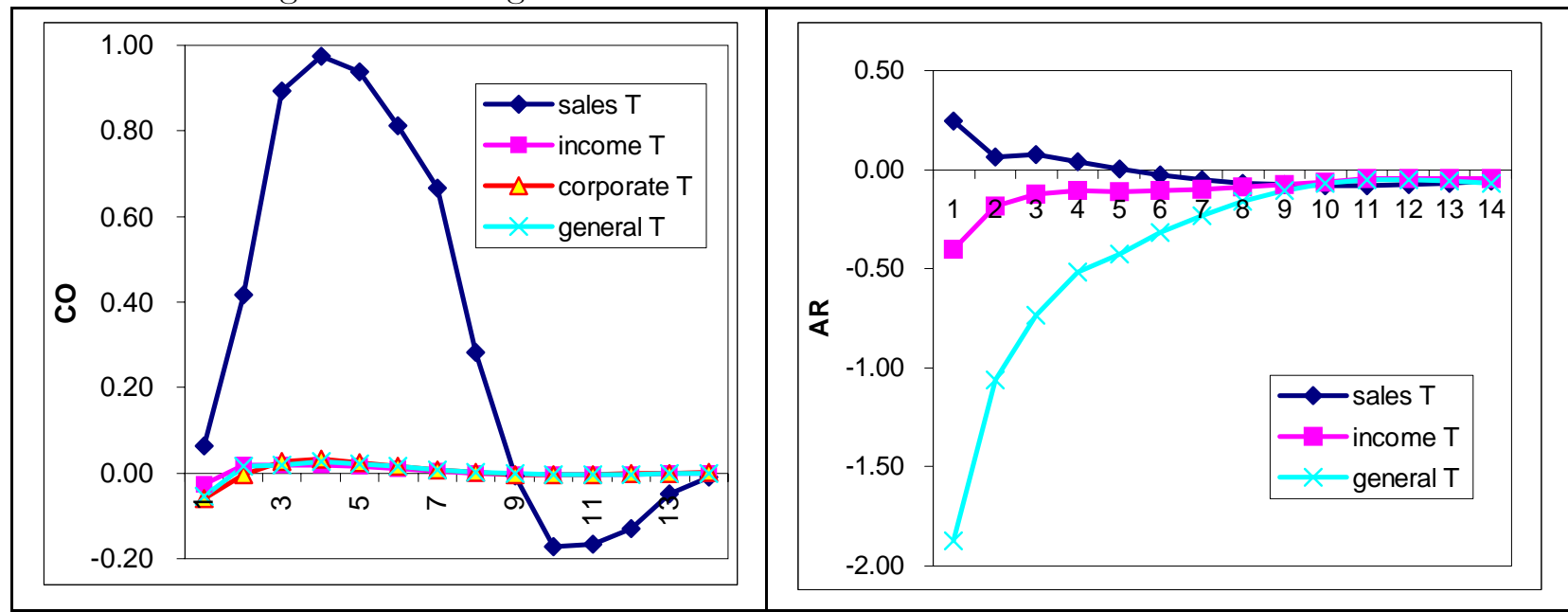

Figure 5: Price differential response to different tax shocks

For EMU countries, the shortness of the sample and the lack of significant independent variations among tax revenue components impede any verification of our conjecture. For US states, where the sample is larger and the variations more significant, we find some support for the argument. In fact, in 5 of the 7 states substituting sales tax revenues to total tax revenue increases price differential while substituting income or capital tax revenues to total revenues leaves the sign of the responses unchanged. To illustrate this fact, figure 5 presents responses in Arkansas and Colorado, when we substitute income, capital or sales revenues for total revenues in the VAR. In both states sales tax

\footnotetext{
${ }^{5}$ Since sales taxes are included in the CPI one should expect to see relative price decrease as taxes decrease in the very short run. However, this effect should dissipate within a year.
} 
shocks increase price differentials while income/capital taxes decrease them.

It is important to stress that neither spillover nor labor supply effects appear to matter for states displaying positive price differentials responses. In fact, in only a couple of cases substituting regional to state prices or changing the type of tax revenues turned price differential responses negative, albeit insignificant. Hence, both mechanisms appear to be important in producing negative price differential responses.

\section{Conclusions}

This paper studied the relationship between local fiscal policy and price differentials in monetary unions using a sample of 47 US states and 9 EMU countries. We identify fiscal shocks using sign restrictions on the responses of output and deficits generated by dynamic stochastic general equilibrium models of fiscal policy. We consider two types of expenditure shocks: those financed by bond creation, which produce positive comovements in local output and deficits; and those financed by distorting taxation, which leave local deficits unchanged and produce negative comovements in local outputs, and one type of revenue shocks, i.e. tax cuts which increase local deficit and output. We construct estimates of the average and of the local price differential responses which reflect local and cross sectional and/or a-priori information.

Our results suggest that fiscal policy is a modest but statistically significant source of price differentials. The magnitude of the effects varies with the unit and the type of shocks but, on average, fiscal disturbances explain between 14 and 23 percent of price differential fluctuations in both unions. Heterogeneities however do exist and there are states (countries) where more than $40 \%$ of the price differential variability is attributable to some fiscal shock. Interestingly, in Ireland and Germany, two countries under EU scrutiny over the period because of their loose fiscal policy, the variability explained by fiscal shocks is negligible.

On average, deficit financed expansionary fiscal shocks increase price differentials, while balance budget shocks (expenditure increases financed by distortionary taxation) decrease price differentials. There are a number of US states and EMU countries where expansionary fiscal disturbances lead to significant decreases in local to union wide prices. Various intuitive explanation based on geographical, political, economic and social indicators fail to explain these puzzling responses. We investigate two explanations based on spillover and labor supply effects and tentatively found both mechanism promising in accounting for perverse price differential responses.

Our results have important policy implications. First, since local fiscal policy has a statistically 
large effect in some states (countries), policymakers caring about regional price differentials may find in our work an empirical justification for imposing limits to both the size and the variability of local fiscal policy. Clearly, our results do not preclude the possibility that one may want to constrain fiscal policy for other reasons (e.g. to enhance the credibility of monetary authorities or to reduce the probability of debt monetization). Second, balance budget shocks have large effects on both local output and local prices. Therefore, our results also warn policymakers against imposing too strict fiscal constraints which, to be maintained, may require dramatic adjustments in the local economy. Third, different fiscal instruments have different effects in the local economy. Deficit financed expenditure shocks produce lagged but more persistent and revenue shocks larger price differential responses. Hence, keeping tax smoothing motives aside, revenue cuts appear to be an important stabilization instrument while expenditure changes could end up having undesirable procyclical effects, especially considering standard implementation lags. In addition, since surprise declines in local income taxes exercise an important effect on the aggregate supply of the local economy, they may provide a useful channel to stabilize overheated economies. Fourth, while there are similarities between the US and the EMU, there are also important quantitative differences. Whether they are due to transitional dynamics, small samples or institutional differences we are not able to tell, given the short experience of the EMU.

This paper is concerned with the somewhat narrow question of whether and to what extent local fiscal policy has effects on local prices. Hence, we did not address the important policy question of whether local fiscal policy should be used to affect local prices. This problem is examined in Pappa (2003). There it is shown that local fiscal policy can be used to stabilize the local price level in response to asymmetric shocks in a monetary union when the central monetary authority is concerned only with union wide price stability and that this course of action optimally allocates the available resources. 


\section{Appendix A: Data sources and definitions}

US data is annual from 1969 to 1995, real, seasonally adjusted, per capita data. U.S. Census Bureau is the source unless it is otherwise indicated.

State Population: total state population in thousands.

Gross state product (in constant 1982 prices): obtained from Bureau of Economic Analysis (BEA) from 1977; before 1977 we used the series from Oved Yosha's US State-Level Macroeconomic Databank (www.tau.ac.il/yosha).

State revenue: total revenue.

State expenditure: direct state expenditure - state capital outlays. Direct expenditure measures all expenditures other than intergovernmental expenditures.

State debt: total debt outstanding at the end of the fiscal year.

State employment: total full and part time state employment (from BEA).

State Prices: state prices are from Del Negro (1998). The price level for state $i$ is computed as:

$$
P_{i t}=w_{i}^{u} P_{i t}^{u}+\left(1-w_{i}^{u}\right) P_{i t}^{R}
$$

where $P_{i t}^{R}$ denotes the price level in rural areas of state $i$ and it is taken from the Monthly Labor Review data of the Bureau of Labor Statistics (after 1978). Before 1978 it measures the "cost of living for intermediate level budget" and the same source is the same. $w_{i}^{u}$ measures the fraction of population living in rural areas of state $i$ and comes from the Statistical Abstract on the percentage of rural population by state. $P_{i t}^{u}$ is constructed as follows:

$$
P_{i t}^{u}=\sum_{k=1}^{K} \omega_{i}^{k} P_{i t}^{k}+\left(1-\sum_{k=1}^{K} \omega_{i}^{k}\right) P_{i t}^{B}
$$

where $P_{i t}^{k}$ is the CPI in metropolitan area $k$, it is obtained from the ACCRA (American Chamber of Commerce Realtors Association) and from the Bureau of Labor Statistics data on CPI for Urban Consumers (CPI-U) and CPI by Regions and by Urban Population. $\omega_{i}^{k}$ is the percentage of urban population living in metropolitan area $\mathrm{k}$ which is obtained from the Bureau of Economic Analysis

site at the University of Virginia. $P_{i t}^{B}$ is the CPI in other urban areas and it is taken from the Monthly Labor Review data of the Bureau of Labor Statistics. State CPI is normalized so that in each year their population average coincides with the US CPI.

State GDP Deflators: computed from real and Nominal state GDP data

US aggregate data for real GDP, interests rate, CPI and oil prices come from the Federal Reserve Bank of St. Louis FREDII data bank. Data on federal expenditures, revenues, deficits and population come from the US Census.

EMU data is quarterly from 1997:1-2003:3, real, seasonally adjusted, and per capita. The Eurostat National Accounts Main Indicator (NAMA_Q) is the main data source unless indicated. 
Population: total country population in thousands from the Quarterly Labor Force Statistics of the OECD

Prices: harmonized consumer price index, base 1996, from the ECB.

Gross domestic product: in constant 1996 prices.

Total revenue: taxes less subsidies on production and imports.

Current expenditure: final consumption expenditure, general government.

Employment: total employment in thousands from the IMF World Economic Outlook.

Union wide interest rate, union wide HICP prices, employment, GDP (base 1996) are from the ECB databank and refer to EUROZONE12 (EUR-11 plus GR up to 31.12.2000 / EUR-12 from 1.1.2001)

\section{Appendix B: Identifying shocks}

The algorithm used to extract fiscal shocks is the following. Let $P_{i, i^{\prime}}(\theta)$ be an orthonormal matrix which rotate columns $i$ and $i^{\prime}$ of the covariance matrix the orthogonalized shocks, $i, i^{\prime}=1, \ldots, 5$. Then:

(i) Draw $\theta \sim U[0, \pi]$ and $i, i^{\prime} \sim U[1,5], i \neq i^{\prime}$, where $U$ indicates a uniform distribution.

(ii) Draw $\alpha_{i} \sim N\left(\tilde{\alpha}_{i}, \tilde{V}_{\alpha}\right)$ where $\sim$ indicate posterior estimates.

(iii) Compute responses to shocks. If restrictions are satisfied, keep the draws and the responses.

(iv) Order the retained responses, extract a measure of location and a $68 \%$ central confidence set. 


\section{References}

Angeloni, I. and Erhmann, M. (2004), "Euro area Inflation differentials", ECB manuscript. Baxter Marianne and Robert King (1993), "Fiscal Policy in General Equilibrium," American Economic Review, 83, 315-335.

Blanchard Olivier and Roberto Perotti (2002): "An Empirical Characterization of the Dynamic Effects of Changes in Government Spending and Taxes on Output," Quarterly Journal of Economics, 117, 1329-1368.

Besley Timothy and Anne Case (1995) "Does Political Accountability Affect Economic Policy Choices? Evidence from Gubernatorial Term Limits" Quarterly Journal of Economics, 110, 76998.

Bryant Ralph, Peter Hooper and Catherine Mann (1993) Evaluating Policy Regimes: New research in Empirical macroeconomics, Washington, D.C., Brooking Institution.

Canova Fabio and Gianni De Nicolo' (2002), "Money matters for Business Cycle Fluctuations in G-7," Journal of Monetary Economics, 49, 1131-1159.

Canzoneri, Matthew., Valles, Javier. and Jose. Vinals (1996), "Computing Value Correspondences for Repeated Games with State Variables. Do Exchange Rate move to address International Macroeconomic Imbalances?" Bank of Spain Working Paper Series, No.9626

Canzoneri, Matthew., Cumby, Robert and Diba, B (2002), "Should the European Central Bank and the Federal reserve be Concerned about Fiscal Policy?", working paper of the Federal Reserve Bank of Kansas City's Symposium on "Rethinking Stabilization Policy."

Cecchetti, Steven., Nelson. Mark, and R. Sonora (2002), "Price Level Convergence Among United States Cities: Lessons for the European Central Bank", International Economic Review, 43, 10811099.

CEPS, (2002), "Fiscal and Monetary Policy for Low-Speed Europe" 4th Annual Report of the CEPS Macroeconomic Policy Group, June.

Christiano Lawrence and Terry Fitzgerald (2000) "Understanding the Fiscal Theory of the Price Level," NBER Working Paper Series, No. 7668

European Central Bank (2003), Monthly Bulletin, April, 22-23.

Dalsgaard, Thomas, Christopher Andre and Pete Richardson (2001), "Standard Shocks in the OECD interlink model", OECD working paper 306.

Del Negro Marco (1998), "Aggregate Risk Sharing Across US States and Across European Countries," mimeo Yale University.

Edelberg, Wendy, Martin Eichenbaum and Jonas Fisher (1999) "Understanding the effects of a Shocks to Government Purchases", Review of Economic Dynamics, 2, 166-206.

Dotsey, Mike (1994) "Some unpleasant supply side arithmetic", Journal of Monetary Economics, 33, 507-524.

Duarte Margarida and Alexander Wolman (2002), "Regional Inflation in a Currency Union: Fiscal Policy vs. Fundamentals," mimeo Federal Reserve Bank of Richmond. 
Fatas Antonio and Ilian Mihov (2001), "Government Size and the Automatic Stabilizers: International and Intranational Evidence," Journal of International Economics, 55, 2-38.

Favero Carlo and Monacelli Tommaso (2002) "Policy Mix and Macroeconomic Stability: Evidence and Some Theory", mimeo, Bocconi University.

Giavazzi Francesco, Jappelli Tullio and Pagano Marco (2000) "Searching for Non-linear Effects of Fiscal Policy: Evidence for Industrial and Developing Countries", European Economic Review, 44, 1259-1289.

Hernandez de Cos, P., Henry, Jerome. and Momigliano, Sandro. (2003)" The short term impact of Government budgets on prices: evidence from macroeconometric models", Bank of Spain, Bank of Italy and ECB manuscript.

Hunt, Benjamin and Douglas Laxton (2002) "Some Simulation Properties of the major Euro area economies in MULTIMOD", IMF manuscript.

Ludvigson C. Sydney (1996) "The Macroeconomic Effects of Government Debt in a Stochastic Growth Model," Journal of Monetary Economics, 38, 25-45.

McGrattan, Ellen (1994) "The Macroeconomic effects of distortionary taxation", Journal of Monetary Economics, 33, 573-601.

Mountford, Andrew and Uhlig, Harald (2002), "What are the Effects of Fiscal Policy Shocks?" CEPR Working Paper, No. 3338.

Neri, Stefano. (2002), "Assessing the Effects of Monetary and Fiscal Policy," Bank of Italy Working Paper, No. 425.

Ohanian, Lee (1997), " The Macroeconomic Effects of War Finances in the United States: World War II and the Korean War ", American Economic Review, 87, 23-40.

Pappa, Evi (2003), "The Unbearable Tightness of Being (in the EMU)," mimeo LSE.

Pappa, Evi (2004), "New Keynesian or RBC transmission? The Effects of Fiscal Policy in Labor Markets", mimeo, LSE.

Perotti, Roberto (2002) " Estimating the Effects of Fiscal Policy in OECD countries", ECB working paper 168.

Ramey, Valerie. and Matthew. Shapiro (1998) "Costly Capital Reallocation and the Effects of Government Spending" Carnegie Rochester Conference Series on Public Policy, 48, 145-194.

Roeger, Werner and Jan in't Veld (2002) "Some Selected Simulation Experiments with the EU commission's QUEST model", EU commission, manuscript. 